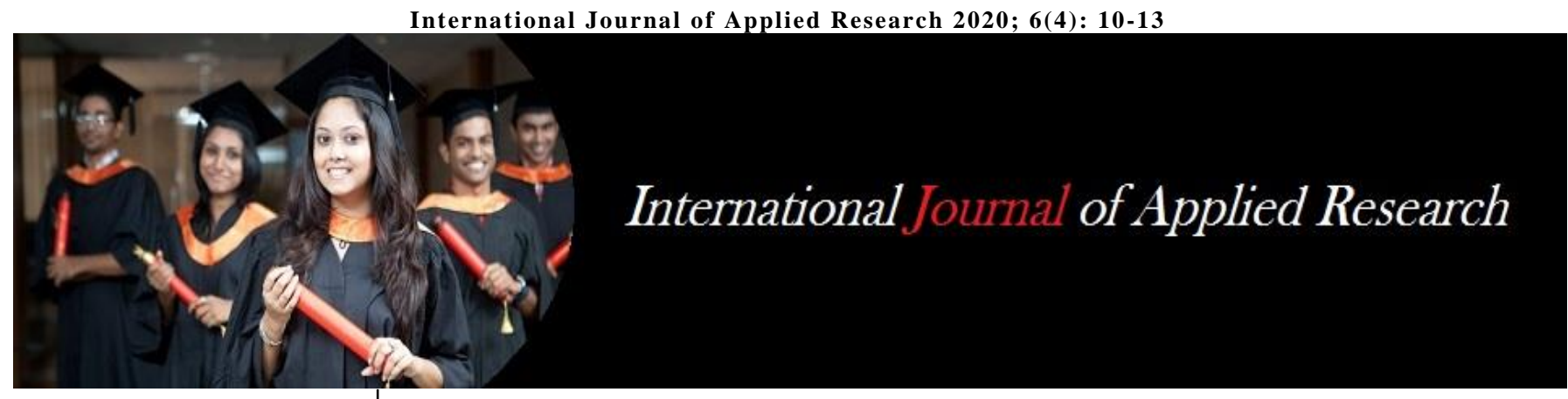

ISSN Print: 2394-7500 ISSN Online: 2394-5869 Impact Factor: 5.2

IJAR 2020; 6(4): 10-13 www.allresearchjournal.com

Received: 08-02-2020 Accepted: 10-03-2020

\section{Joheb Islam}

Assistant Professor (WBES),

Dept. of Sociology, Nayagram

Prm Govt College, West

Bengal, India
Correspondence Author: Joheb Islam

Assistant Professor (WBES), Dept. of Sociology, Nayagram Prm Govt College, West Bengal, India

\section{Social change of the Kurdmi-Mahatos in west Bengal: A sociological study}

\section{Joheb Islam}

\begin{abstract}
Role of the masses in social transformation had been recognized by the mid-nineteenth century. There are three approaches to study social movements: historical, psychological and sociological. Historians try to understand the life-cycle of a movement. They pose the question: how did movements get institutionalized? They try to analysis motives and beliefs of the participants who are the parts of the masses which can be mobilized into collective action. Sociological approach tries to analyses the development of an ideology and its functions to the group which adheres to it, and more generally the conditions under which a group will fight in the name of a set of beliefs. A sociological approach to social movements presupposes a theory of society because collective action is possible responses to crises, which occurs in society. The base of these crises may be found into the wide range of societies and its different structures of deprivations. The main concern of this study is to understand KudmiMahata's social transformation comparing the model of sanskritization.

In the case of Kudmi-Mahatas, an identity crisis may be occurred as there is a mismatch of identity. The older generation wants to be identified as 'Hindu Kshatriya' while the younger generation as 'totemic Kudmi tribal'. Therefore, it is an example of 'status-deprivation' which creates an identity crisis among the Kudmi people. To restore their aboriginal identity they have started a process of cultural revivalism through their scripts and languages and festivals from first half of previous century. Therefore, in this paper author has tried to understand two ways of social change among this community.
\end{abstract}

\section{Keywords: Social change, sanskritization, tribal movement}

\section{Introduction}

In post-independent and post-colonial India, society had been gone under massive transformation due to globalization and information revolution. The process of Westernization, Modernization and Globalization made changes in the profiles of all cultures of primitive, post-primitive and modern society. Tribal society is no exception in this scenario. Renounced sociologists like Nirmal Kumar Bose and M.N. Srinivas introduced us with few of the changes occurred among tribal and cast societies in India through their famous works namely 'The Hindu Method of Tribal Absorption' and 'Sanskritization'. The general assumption of their work is that tribal society exists in the lower ladder of the evolutionary process. Hence, it must be move into the upper level of society and would leave their past culture (Atal 2016, pp.20). This assumption ruled over Indian sociology and socialanthropology for several decades in studying tribes and castes. A new twisting and interesting matter has been witnessing in Indian society for recent few years which provoked sociologists and anthropologists to look tribal group of people with a fresh perspective. Few communities in India are demanding for inclusion into the Schedule for the tribes by showing various justifications. Professor Yogesh Atal had witnessed similar case when he was invited by the Government of Rajasthan to assess tribal status of a claimant group. The Gujjars in Rajasthan has been showing agitation for several years demanding tribal status. When Prof. Atal was invited by the Government of Rajasthan to serve on a Three-Member Committee set up to examine the candidature of the Gujjars as a tribe, he was surprised not founding any study, research or $\mathrm{PhD}$ work undertaken by any institute or researcher carried out on this community. In his own words, "Anthropology was expected to provide a dependable answer, but it had nothing to offer" (ibid). Therefore, focusing on the changes in ethnic elements will lead us to understand the 'transitional structure' of a tribal community. 


\section{Review of literature}

To understand today's 'claimant group' (Gujjars or KurdmiMahata) of tribal status, that is the community in question and it's reality, we have to gone through the past sociological and anthropological works done on tribe. The general academic assumptions about tribes may be sum-up as a simple cluster of people which is governed by the bonds of kinship, unique language, distinctive religious belief, different pattern of customs and rituals, distinct taboos and a common name (Pathy, 1920:50). The whole conceptual paradigm about tribes in India and its study is based on the colonial line of enquiry. "Students of natural history and anthropology welcomed the opportunity to carry out investigations of their subject matter in strange settings to further exemplify the theory of evolution as developed by Charles Darwin in his On the Origin of Species. The key concept of Natural selection and Survival of the Fittest used by Darwin to explicate his theory of evolution were found useful in building an evolutionary ladder for human societies putting the savages at the bottom, barbarians in the middle and the civilized peoples in the top. The colonial administrators used this framework to justify their superiority and the legitimacy of their rule over the colonies [i]" (Atal, 2016:10).

Following the above line of enquiry, a large number of anthropological works of the post-independent India, points out to the phenomena such as tribes are being absorbed into the Hindu society or tribes becoming caste. Surojit Sinha (1958) views tribes as dimension of little tradition that cannot be adequately understand unless it is seem in relation to the great tradition. Betteile (1986:316) opposed this notion and views tribes as a matter of remaining outside of state and civilization where tribe and civilization co-exist, as in India. N.K. Bose (1941) makes reference of tribes which were being absorbed into the Hindu society by accepting the ethos of caste structure. Some of the well-known tribes in this category are Bhils, Bhumijs, Majhi, Khasa and RajGond ${ }^{[i i]}$. Similarly, Roy Burman (1972) in his earlier work classified tribes as those incorporated, positively or nagetively oriented and indifferent to the Hindu society. The same assumption is followed by Vidyarthi (1977), Elwin (1944) and Kosambi (1975) in their works. All of them questioned for tribal absorptions into the Hindu society.

Bose has clarified about the mode of tribal absorption into the Hindu society in detail, in his book titled, Tribal Life in India. A slow but continuous communication between simple cultivating tribes and specialized peasants or artisans must have gone on for centuries (Bose, 1971. pp.21). The basic purpose of this relationship is to secure food for all the tribesmen in a community as Bose (1971) has pointed out in his work, titled 'Tribal life in India', “...the changes to which tribal communities were subjected under the superior pressure of the more efficient productive organization built up by the Hindus". Majority of the tribes like Juangs of Orissa, Gonds of Madhya Pradesh and the Santals of Bihar or Bengal have come within the 'orbit of the peasant civilization of the Hindus' (Bose, 1971.pp.22) ${ }^{\text {[iii] }}$

According to Bose a caste-class relation is important in classifying castes among transformed tribes. "The upper classes were given the status of Kshatriyas, perhaps after a purificatory fire-worship, when a genealogy was also prepared for them from some mythical ancestor by unemployed Brahmans who were on the look-out for new clients." Except upper class families or lineage, the majority of the tribes then were found a place in the Sudra varnas. In terms of occupation all were not cultivators or landlabourers. Some of them were specialized in works like basketry and blacksmithery, and were reckoned as artisan castes (Bose, 1971.pp.26).

The reasons behind tagging a caste name after certain occupations is, “...that when a tribe gradually adapts itself to a local economic situation by specialization in a particular occupation, that occupation is generally regarded as its monopoly, unless it is something like agriculture..." as explained by Bose (1971) in his 'Tribal Life in India'. The Hindu notion of 'purity' and 'pollution' have been invaded into the religious system of Birhors of Orrisa and Hazaribagh when they fenced off a few square feet of land and marked it as a sacred spot- the seat of the Goddess Durga (Bose, 1971.pp.32). Thus, by following endogamy marriage, occupying agriculture and other specialized works and adapting Hindu belief system, the Birhors had 'started looking upon themselves as another Hindu jati or caste'.

According to the above sociologists and anthropologists, the absorption into the Hindu society has been happened through complexity of the social processes. These social processes have been termed as Sanskritisation ${ }^{[i v]}$ by M.N. Srinivas in his study of The Coorgs. Anthropologists have also used specific terms as Kshatriyisation or Rajputisation in the place of sanskritisation.

The point is that sociologists and anthropologists assumed this process of tribal transformation as social change within caste system. They assumed the same theory of evolutionary ladder as used by the colonial masters which justify the rule of civilized people. But, this line of logic is inappropriate in the sense that a tribal community has been counted under the caste hierarchy and part of Hindu society. But, the tribe is a society that remains outside the caste-Hindu society. In order to be sanskritised or kshatriyised, they must be included into the caste-Hindu social structure first.

Therefore for a student of sociology and anthropology, one needs to study tribes from two perspectives, as Yogesh Atal guided us in his work 'Indian Tribes in Transition. According to him, "there is a need to differentiate between two concerns, namely that of recording for our posterity the prevailing patterns of behaviour and elements of material culture as part of human history, and of documenting the process of change and transformation that various communities are undergoing" (Atal2016, pp.20). The present study need to follow the last stand as guided by Yogesh Atal.

\section{Research Objectives}

Considering present-day Kurdmi-Mahata's concerns and with the limitation of ethnographical evidences, this study has certain research objectives. These are as follows:

1) The present study has focused on the community in question with a fresh perspective considering tribe as a 'transitional structural unit' and see the level of transformation in the sphere of beliefs, rituals and social practices. And,

2) This study has been seen how much ethnic (dialects, festivals, religion, rituals, morals, and social organization) elements still exist among the community.

\section{Methods of data collection}

For this study, methods of data collection consists of unite of analysis, sampling frame, sampling design, sample and observation methods. 


\subsection{Unite of Analysis}

The Unite of analysis for the present study has been taken from three villages namely Kurmipathra village of the district of Jhargram, Midnapore town of West Medinipure district and town Purulia of Purulia district in West Bengal.

\subsection{Sampling Frame}

As the entire names of the individuals should be listed in a sampling frame, then the voter list has been taken as a sampling frame for this study. Total population of the three villages is 1045 .

\subsection{Sampling Design}

As the study is qualitative in nature, the sampling frame must be of non-probability sampling. Hence, Quota sampling technique is appropriate for this study. In Quota sampling researcher will first define the groups and specify the sizes, and then individuals who fit those descriptions will be selected to fill the quotas. For this study variables like age, sex, occupation and land holding will be appropriate as quota to see the different point of view for those engaging in the social movement.

\subsection{Sample}

$3 \%$ of the total population has been selected as the sample for this study.

\subsection{Method of data collection}

As the researcher has been living with the Kurmi-Mahata in one village and at one of their home for more than four years, he has the opportunity to observe their day-to-day living, social practices, rituals and beliefs. Hence, observation method along with unstructured schedule and interview methods have been best suited for this type of study.

\section{Report based on a field study}

The main objective of this study is to get the region wise commonality of the on-going Kurdmi-Mahata transformation process and movement. Beside this, the study takes account of beliefs, participation in festivals, rituals, recent crises and participation in movements among Kurdmi-Mahata. The commonalities of all three regions may be pointed out as -

a) All of them believe in their family totem.

b) All of them believe that they are the aboriginals of Chotonagpur plate and migrated to different regions of the country for occupational purpose.

c) Kurmali is their group language.

d) Aboriginal occupation is cultivation.

e) 'Saran' is their aboriginal religion.

f) All believed that they should establish their aboriginal identity.

\subsection{Kurmi-mahata's social transformation}

The Kurdmi-Mahata was originally an aboriginal peasant which can be established by the secondary data. Among the thirty respondents, all have stated that agriculture was their forefather's only occupation. Up to the last decade of nineteenth century they follow their tribal way of life. They follow exogamy marriage pattern. 'Majhi' was the cheap of their society. A 'Majhi' can be any elder member of a family, or of a group. There was no role of Brahmin in their rituals and functions. But, due to the impact of colonization and other political issues and of course of the process of 'Sanskritization' the homogenous society of adivasi Kurdmi-Mahato had been changed and moved upward in social position as they got the 'Kshatriya' status. It should be noted that all the Kurdmi had not become 'Kshatriya'. Few of them still followed their group culture and rules. Therefore, there was a divide between the homogenous Kurdmi-Mahatos as i) 'Boro-Kurdmi', means those who transformed as an upper caste and managed an upper position in society; and ii) 'Choto-Kurdmi', those who did not transformed as Kshatriya ${ }^{[\mathrm{v}]}$. The last section was a weaker one in social prestige, position and power ${ }^{\text {[vi] }}$. This section started functions to regain their original identity form the very beginning of $1931 \mathrm{~s}{ }^{\text {[vii] }}$. They still follow their aboriginal festivals like 'Tusu' and many more. So, there is a wide range of social and cultural transformation among the Kurdmi-Mahatos.

\section{Conclusion}

The present study has focused on the processes of transformation of Kurdmi-Mahata community and its way of life through their past and present movements. The communities like Gujjars in Rajasthan and Kurmi-Mahata in West Bengal are the similar cases where a community wants to look back to their roots. But, "we need to insist that there cannot be a path of reversal, or moving backward. It is wrong to assume that once a tribal is always a tribal. If we took recourse to the history, each one of us can claim to have belonged to one tribe or the other just as the Gujjars are doing today, even after enjoying the status of a Hindu or a Muslim caste for several generations (Atal, 2016.pp.20)." But, the nature of the problem witnessing in the cases of Gujjars and Kurdmi-Mahats, draw our attention to study 'tribe' and to reassess the pattern of transformations happening among these groups of people. In Yogesh Atal's won words, "It is time that we, as social scientists, propose the definition of tribe as a transitional structural unit and focus our attention on the study of the processes of its transformation into a larger society as well as its assimilation as a subset in a larger social system. These developments require a change in the paradigm for the study of tribes" (ibid).

\section{References}

1. Atal Y. edit. Indian Village Revisited by Brij Raj Chauhan. Institute of Social Development. Jaipur: Rawat Pub, 2018.

2. Atal Y. Indian Tribes in Transition: The need for reorientation. New Delhi: Routledge, 2016.

3. Beteille A. Six Essays in Comparative Sociology. Delhi: OUP, 1974.

4. Bose NK. Tribal Life in India. New Delhi: NBT, 1971.

5. Bose NK. The Structure of Hindu Society. New Delhi: Orient Longman ltd, 1975.

6. Hasnain N. Tribal India. New Delhi: Palaka Prakashan, 2017.

7. Mahato PP. Bharoter Adivasi O Dalit Samaj. Kolkata: Purbalok, 2012.

8. Rao MSA. Edit. Social Movements in India. New Delhi: Manohar, 2016.

9. Roy BK, Burman. Basic concepts of Tribal welfare and Tribal Integration. Journal of Social Research. 1960, III.

10. Singh Yogendra. Social change in India: Crisis and Resilience. New Delhi: Har-Anand, 2011. 
11. Singh KS. Edit. Tribal Movement in India. New Delhi: Manohar, 2015; 1-2.

12. Munshi Surendra. Tribal Absorption and Sanskritization in Hindu Society in Contributions to Indian Sociology. 1979; 13:293.

http://cis.sagepub.com/content/13/2/293.

\section{Notes}

${ }^{i}$ Atal, Y. (2016). Indian Tribes in Transition: The need for reorientation. New Delhi: Routledge.

ii Bose, N.K. (1971). Tribal Life in India. New Delhi :

NBT

iii Ibid.

iv Srinivas, M.N. (1966). Social Change in Modern

India. Hyderabad: Orient BlackSwan.

${ }^{v}$ Field data.

${ }^{\text {vi }}$ Singh and Mahato, 2015.

vii K.S. Singh, 2015 